\title{
Design of Automatically Sprinkling Irrigation System to Water Saving in Greenhouse
}

\author{
T.T. Dong, X.S. Zhao, Z.K. Ma, H.L. Yu, Y. Liang \\ College of Mechanical and Electrical Engineering \\ Agriculture University of Hebei \\ Baoding, China
}

\begin{abstract}
In our country, irrigation mode in the greenhouse is still flood irrigation, which not only wastes water resources in short supply, but also restricts the increase of the crop output and the improvement of its quality in the greeenhouse. The paper used sensor technology to real-time do acquisition of the temperature and humidity of air, the moisture content of soil and the illuminance in the greenhouse. The SCM (Single Chip Micyoco) gived a reasonable control decision by analysing these data to do automatically sprinkling irrigation by control the actuator. The system achieves computer automatic control, sprinkling irrigation by need, time and quantity. It is energy-saving, environmental protection, labor saving, so the system has a certain practicality and potential popularization.
\end{abstract}

Keywords-greenhouse; sprinkling irrigation; water-saving; temperature; humidity

\section{INTRODUCTION}

Irrigation is a significant factor influencing greenhouse production benefit. Application of micro-irrigation control in the greenhouse ensures water requirements of greenhouse crops, promotes water utilization rate and efficiency, controls crops growth environment microclimate for water saving, increase of productivity and income, and ecological environment benefits [1]. Presently in China large areas of greenhouses remain traditional flooding irrigation, of which water utilization rate is only $20 \%-30 \%$. Plant root system is under the ideal condition of moisture and temperature combination only in $40 \%-50 \%$ period of time [2]. Soil hardening, nutrition loss, large irrigation amount, and large amount of fertilizer usage are serious results of long-term usage of border irrigation and furrow irrigation. Because of synchronous increase of irrigation amount with soil moisture and air humidity, it is easy to encounter high temperature, high humidity, plant diseases and insect pests, especially uncontrollable cucumber downy mildew and seedling blight, which lead to the increasing amount of pesticide with years [3]. Therefore traditional irrigation method has restrained the promotion of greenhouse crops yield and quality. In recent years, with the popularization of micro-irrigation technology in China, people realize that this technology can not only save water but also provide best service for agriculture development [4]. Popularization of modern water saving irrigation technology in the greenhouse will be effective to stable development of water saving agriculture in China. Water utilization rate is above $90 \%$ [5].

Sprinkler irrigation is one of the earliest and most universal water saving irrigation method that provides necessary water for plant growth. It can adjust greenhouse microclimate, increase air humidity and lower air temperature. Practices show that sprinkler irrigation increases 15-25\% crops yield than those by land irrigation [5]. Presently in China greenhouse water saving sprinkler irrigation system has poor automaticity and there is no fashioned auto-control sprinkler irrigation system, basically operating by artificial irrigation or manual valve. Considering the abovementioned situations, in this article it designs greenhouse automatic spray irrigation test and control system, which timely and properly controls water for greenhouse crops by real-time monitoring of air temperature humidity and soil moisture.

\section{SPRINKLER IRRIGATION SYSTEM OVERALL STRUCTURE} DESIGN

This system is composed of greenhouse environmental information acquisition module, singlechip AT89C52 module, and control module. The acquisition module includes illuminance sensor, soil moisture sensor, air temperature and moisture sensor. The illuminance sensor adopts silicon photocell 2DU6 as photoelectric sensor device and soil moisture sensor applies TDR-3 that Jinzhou Sunshine Technology Development Co., Ltd. developed. As these two types of sensors outputs are analogs, it needs to transfer to singlechip AT89C52 after the pretreatment of signal modulate circuit and A/D conversion. Acquisition of greenhouse environment air temperature and moisture takes temperature moisture all-in-one digital sensor SHT71 and directly outputs digital to singlechip AT89C52. Control module is composed of photoelectric coupler, electrical relay, and performer. The overall structure is shown in Figure 1.

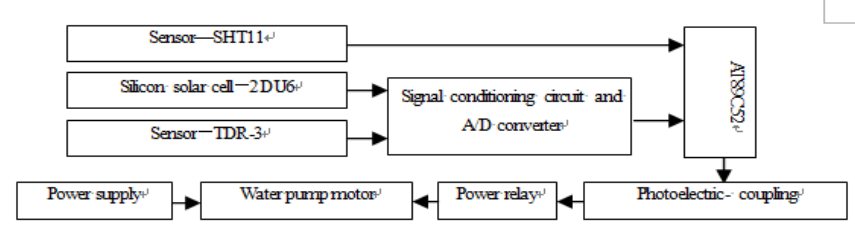

FIGURE I. THE HARDWARE BLOCK DIAGRAM OF THE SPRINKLING IRRIGATION SYSTEM. 


\section{SIGNAL ACQUISITION SYSTEM}

\section{A. Illuminance Acquisition Module}

Illuminance is one of the significant parameters in crops growth environment, playing a role of participation and adjustment in germination, seedling growth, leaves expansion, chloroplast development, bloom and fruition, especially in Northeast China of short illumination period and cloudy rainy South China. What's more, different crops need different strong or weak illumination. Therefore detection and supervision of illuminance in facility agriculture obtain more and more attention.

The system taking silicon photocell 2DU6 as photoelectric sensor, it amplifies short circuit current signal to $0 \sim 5 \mathrm{~V}$ and transfers to singlechip AT89C52 through A/D module. Because silicon photocell has the characteristic that open-circuit output voltage is nonlinear, when illumination intensity is 2000lx, it tends to be saturated and cannot directly amplify the signal. Changing with illumination intensity, silicon photocell short circuit is of linear variation. Photoelectric battery in different illumination intensity has different essential resistance. Therefore it shall select proper external conjunctive load to approximately meet the condition of "short circuit". A/D converter can only accept voltage signal, so it requires an electric current voltage conversion circuit between silicon photocell 2DU6 and singlechip AT89C52. This electric current voltage conversion module uses amplifier OP777. The circuit figure is shown in Figure 2.

\section{B. Soil Moisture Acquisition Module}

The detection of soil moisture in water saving automatic spray irrigation system is the most important. The signal accuracy has direct relation to water saving degree and automaticity. To measure soil moisture rapidly and accurately is significant to investigate soil moisture balance of crops in growth and development stages in order to make decisions of irrigation, fertilizer or drainage measures. Moisture) is the main factor to determine soil specific inductive capacity. To measure it can directly and stably reflect real water content of various soils. The system uses TDR-3 soil water content sensor. Circuit figure is shown in Figure 3.

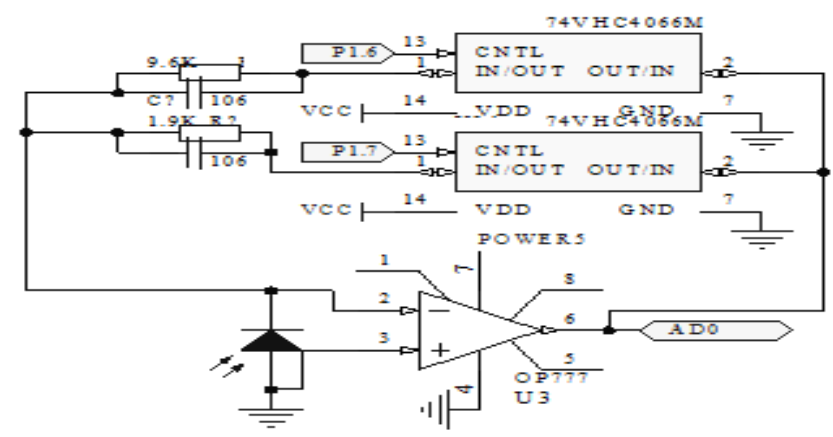

FIGURE II. THE CIRCUIT FIGURE OF THE ILLUMINANCE ACQUISITION MODULE.

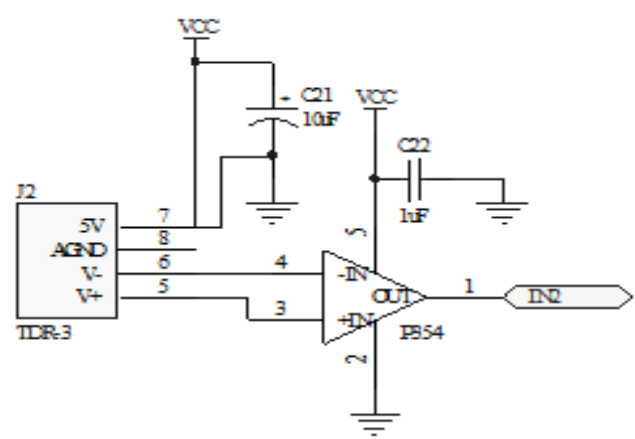

FIGURE III. THE CIRCUIT DIAGRAM OF THE SOIL MOISTURE ACQUISITION MODULE.

\section{Temperature and Moisture Sensor}

The system uses integrative temperature- moisture digital sensor SHT71 that highly integrates temperature and moisture sensor, amplifier, A/D converter, standard data storage device, I2C bus into one chip and needs no peripheral circuit. The sensor directly outputs digital signals of calibrated relative moisture and temperature. This temperature and moisture sensor uses typical industrialized CMOS technology to ensure extremely reliability and long-term stability. The whole chip includes calibrated relative moisture and temperature sensors, which are connected with one 14-bit A/D converter and one I2C bus serial interface circuit. Each sensor is calibrated in precise moisture room. Calibration factors are memorized in sensor OTP memory in advance, which are used in the whole process of measuring calibration. The circuit figure is shown in Figure 4[6].

\section{CONTROL SYSTEM}

The sensor collects each parameter value of greenhouse environment. After the processing, the single chip figures out the best sprinkler irrigation strategy, giving control signal to the executive device. This design drives electrical relay output by photoelectric isolation. The photoelectric coupler adopts TLP521-4 and electrical relay JZC-23F. The contact power is SA/220VAC. Figure 5 shows the illustrative Figure of the interface circuit.

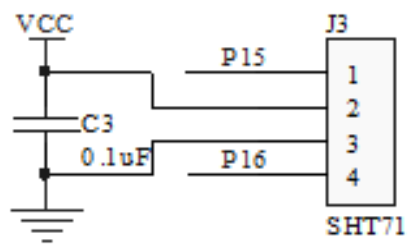

FIGURE IV. THE CIRCUIT DIAGRAM OF CONNECTING SHT71 WITH SINGLE-CHIP. 


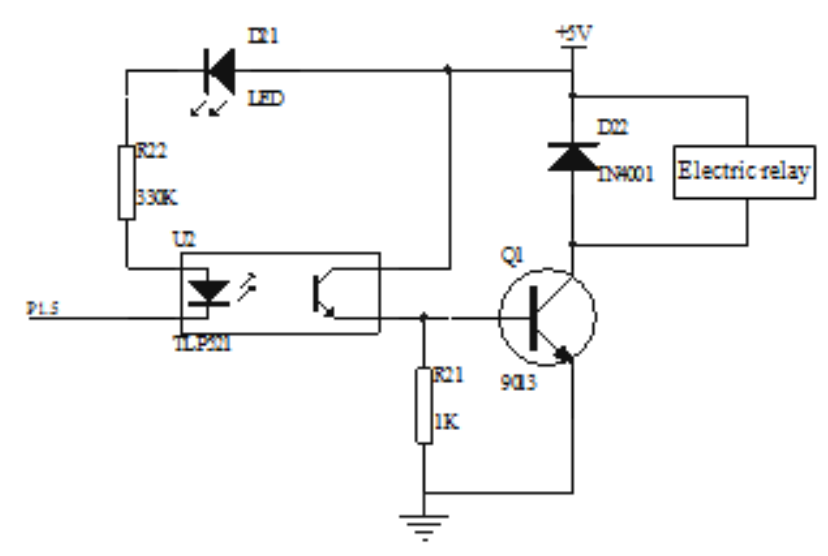

FIGURE V. THE INTERFACE CIRCUIT DIAGRAM OF THE CONTROL SYSTEMS.

When the singlechip electrifies, its $\mathrm{I} / \mathrm{O}$ port is in the input state. To ensure the electrical relay has no misoperation when the singlechip resets, the system adopts low level efficient output mode, and it sets I/O port output power level to high level at the system initialization. When the singlechip resets and electrifies, the optocoupler is in the non-conducting state, and the electrical relay doesn't work. When it needs the electrical relay to operate, it sets relevant $\mathrm{I} / \mathrm{O}$ port of the singlechip to low level.

When the input is in low level, the optocoupler turns on, and the output is in high level. At that time, dynatron 9013 saturates and conducts, and the electrical relay actuates. When the input is in high level, the dynatron cuts off, the electrical relay releases and it accomplishes the whole process, of which diode IN4001 in parallel is follow current diode for protection. When dynatron becomes cut-off from turn-on, electrical relay generates strong opposing electromotive force to maintain electric current, which will be easy to break down the dynatron. After paralleling diode IN4001, it provides discharge circuit for this back-EMF to protect the dynatron.

\section{CONCLUSION}

In this article it combines sensor technology with computer technology and sprinkler irrigation technology. It designs automatic spray irrigation system for greenhouse crops water saving irrigation for periodical sprinkler irrigation according to necessity and quantity to promote crops yield and water utilization rate, to save precious water resources and labor cost. It is practical and promotional, having favorable economic benefits and social benefits.

\section{ACKNOWLEDGMENTS}

The authors thank the Science and Technology Project of Baoding City (14ZN008) for support.

\section{REFERENCES}

[1] Gao Zhaoyang, Li Baoqian \& Mai Kaile. Design and Study on Automatic Control System of Dual Humidity Based on Greenhouse Microirrigation. Journal of Agricultural Mechanization Research, 30(9), pp.116-119, 2008.

[2] Chen Wenqing. Research and application of automatic control system for water saving irrigation. Water Saving Irrigation, (6), pp.27-29, 2004.

[3] Li Yanjun \& Wei Chunyun. Discussion on the necessity and feasibility of promoting micro-irrigation in greenhouse in cold area. Water Saving Irrigation, (6), pp.8,1998.

[4] Chen Lei. Vigorously popularize water-saving irrigation technology. Farm Machinery, (9), pp.4-6, 1999.

[5] Pu Qing. Study and Design of Tunnel Greenhouse Environment and Drip Irrigation Control System Use P87C552 Microcontroller, 2007, Nanjing Agricultural University, Nanjing, China.

[6] Yu Huali, Zhao Xiaoshun, Liu Shuxia, et al. Application of the Sensor SHT71 in the Temperature and Humidity Environment Measuring System. Journal of Agricultural Mechanization Research, 30(5), pp.151-153, 2008. 